\title{
Bio dynamic farming: a future agriculture farming
}

\section{Opinion}

In present agriculture scenario the China ranks first and India ranks second worldwide in farm output. With 2.6 billion people, India and China account for $35 \%$ of the world's population. China alone feeds $22 \%$ of world population with only $10 \%$ of the planet arable land but 60.3 percent of India's land area is agricultural land as "share of land area that is arable, under permanent crops, and under permanent pastures. At 157.35 million hectares, India holds the second largest agricultural land globally which show more chances to feed growing population with enhanced productivity. But at present the use of agricultural chemicals has significant effect on food chain and micro-organisms of the soil. Further, depletion of non-renewable sources of energy and escalating price of fertilizers are the issues of concern with respect to agricultural productivity. Because of chemicalization of agriculture has resulted in the deterioration of soil health, thereby culminating environmental pollution and stagnation in the productivity. Indiscriminate use of agro-chemicals during the last 5-6 decades has adversely affected the soil fertility, crop productivity, produce quality and particularly the environment.

Annually India is losing nearly 0.8 million tones of nitrogen, 1.8millions tones of Phosphorus and 26.3million tones of potassium. Soil organic carbon content in most of the Indian soils has been reduced to $>0.5$ per cent. Under dwindling natural resources the green revolution is exhibiting second generation problem owing to over exploitation and mismanagement of soil by which the ecological principles are damaging.

To be sustainable, a given land must produce adequate yields of high quality, be profitable, protect the environment, conserve the resources and be socially responsible in the long term. Under these circumstances, maintenance of soil fertility and crop productivity are the major constraints in future agriculture for healthy food and wealthy environment for growing population.

The aforesaid points have necessitated for the alternatives focusing on the use of available renewable sources of plant nutrition for sustainable agricultural production. So, looking at various options, the solution available is the integration of crops and livestock, recycling of nutrients, maintenance of soil, and the health and wellbeing of crops and animals only by the viable option to tackle the problem and to renovate our ravaged planet into synthetic chemical free healthy food and wealthy environment. To achieve above objectives, biodynamic agriculture appears to be one of the sound alternative. Biodynamic farming is based on systematic and synergistic harnessing of energies from cosmos, earth, plant and cow. Biodynamic farm is a self-sufficient unit, a closed ecosystem that produces its own compost, seeds and livestock. It operates within the larger context of the local community and the rhythms and relationship of nature and the cosmos. It has been observed that these practices do not require sophisticated facilities and most of them can be created on farm itself by simple effort which can capable of affording long-term sustainability to agriculture and particularly to the ecosystem.

In 1920s Rudolf Steiner initially developed the biodynamic agriculture or biodynamic farming. According to recent data biodynamic farming techniques were used on 161,074 hectares
Volume 6 Issue 2 - 2017

\author{
J Shankaraswamy, SV Mantena and KB \\ Arakeri \\ Amity International Centre for Postharvest Technology and \\ Cold Chain Management, Amity University, India
}

Correspondence: J Shankaraswamy, Amity International Centre for Postharvest Technology and Cold Chain

Management, Amity University, Noida, UP 201313, India, Tel +9|962-663-443-9, Fax +91-120-439-2502,

Email shankara.swamy@gmail.com

Received: January 30, 2017 | Published: January 30, 2017

in 60 countries. Germany accounts for $45 \%$ of the global total; the remainder average 1750 ha per country.

Those unknown with biodynamic agriculture might question, "Just what is biodynamic agriculture?" Biodynamic and organic are very similar; both are grown without chemicals and GMOs. However, biodynamic goes one step further. It is a holistic practice where all things are considered living interrelated systems-animals, plants and the solar system. Biodynamic practices create healthier plants and heal the earth by replenishing the soil and adding vitality to the plant, soil and/or livestock.

The main difference between biodynamic and organic is that biodynamic farming uses different principles that add vitality to the plant, soil and livestock, whereas traditional farming typically deteriorates the soil. Biodynamic agriculture uses specifically prepared preparations made from minerals and herbs (plant material such as flowers from compositae such as Tridex procumbens, Ageratum conzyzoides and leaves of Casuarina sp. were explored for its potentials in biodynamics ) very similar to homeopathy. These preparations are used to enhance the compost applied to the fields and intensify the sunlight permeated into the plant.

\section{Important components of biodynamic farming}

i. The 'biological' practices usually include a series of organic farming techniques that improve soil health, while the 'dynamic' practices are intended to promote the metaphysical aspects of the farm, e.g., planting seeds during certain lunar phases to adapt to the natural rhythms of the planetary system

ii. Turning in plant materials such as green crops and straw

iii. Not using chemical fertilizers and pesticides

iv. Avoiding soil compaction by machinery or animals, particularly in wet weather

v. Keeping soil covered by pasture, crops or mulch not destroying the soil structure by poor farming practices such as excessive use of rotary hoe or cultivation in unsuitable weather (too wet or too dry) 
vi. Fallowing the land by planting deep-rooting permanent pasture species or using green crops

vii. Use of preparations BD-500 and BD-501

viii. Compost made with preparations BD-502 - BD-507

ix. Liquid manure made with preparations BD-502 - BD-507

x. Cowpat pit manure made with preparations BD-502 - BD-507.

\section{Biodynamic formulations}

Many efforts are made to restore soil fertility in the form of humus, increase in living system of soil by skillful application of appropriate crop rotation. BD preparations had 3.2410 to $6.9010 \mathrm{~g}-1$ of bacteria antagonistic to disease causing fungi.

Biodynamic agriculture are coded formulations/ preparations BD 500 through BD 507, comprising cow manure and herbal formulations. These biodynamic formulations are not food for the plants, but they facilitate the effective functioning of etheric forces. They are also not the usual compost starters, but can stimulate compost organisms in various ways. In short they are biologically active dynamic preparations which help in harvesting the potential of astral and ethereal powers for the benefit of the soil and various biological cycles in the soil. So far 9 biodynamic preparations have been developed, named as formulation 500 to 508. Out of these, formulation-500 (cow horn compost) and formulation- 501 (horn-silica) are very popular and are being used by large number of biodynamic farmers. Formulations-502 to 507 are compost enrichers and promoters, while formulation 508 is of prophylactic in nature and helps in control of fungal diseases.

Since all biodynamic farms may not be able to develop the preparations on-site, a commercial source for $\mathrm{BD}$ preparations are now new startups alongside the facilities for the range of biodynamic preparations, ensure the steady supply to organic farms in all countries and abroad. Biodynamic Agriculture is capable of meeting the present and future issues and could afford sustainable agriculture for future with more nutritious food for livelihood.

\section{Acknowledgements}

None.

\section{Conflict of interest}

The author declares no conflict of interest 